\title{
METAMATERIAL LOADED MICROSTRIP PATCH ANTENNA FOR QUAD-BAND OPERATION
}

\author{
Prashant R. T ${ }^{\mathbf{1}}$, Vani R. $\mathbf{M}^{\mathbf{2}}$, Hunagund P. $\mathbf{V}^{\mathbf{3}}$ \\ ${ }^{1}$ Research Student, Dept. of Applied Electronics, Gulbarga University, Gulbarga-585 106, Karnataka, India \\ ${ }^{2}$ Professor \& Head, University Science Instrumentation Center, Gulbarga University, Gulbarga-585 106, Karnataka, \\ India \\ ${ }^{3}$ Professor, Dept. of Applied Electronics, Gulbarga University, Gulbarga-585 106, Karnataka, India
}

\begin{abstract}
In this paper, a novel design for miniaturization of microstrip patch antenna with multiband operation of microstrip antenna is proposed. The technique is based on etching out of Complimentary Split-Ring Resonator (CSRR) on the radiating edge of the patch antenna. Numerical simulations are presented for a patch antenna with and without CSRRs by using IE3D simulation software and measured practically. The measured results shows that antenna with CSRRs on the radiating edge of the patch antenna is resonating at four different frequency points i.e., $4.96 \mathrm{GHz}, 6.05 \mathrm{GHz}, 8.62 \mathrm{GHz}$ and $11.25 \mathrm{GHz}$., whereas, antenna without CSRR i.e., conventional microstrip antenna is resonating at 5.98GHz. The size reduction of $16.92 \%$ is achieved and the antenna gives the overall bandwidth of $17.88 \%$. These antennas find application in Wireless Communications.
\end{abstract}

Keywords: microstrip antenna, CSRR, return loss, miniaturization, bandwidth.

\section{INTRODUCTION}

Microstrip patch antennas are very attractive candidates for use in modern wireless communication systems due to their moderate performance and ease of integration with microwave devices. Nowadays, with trends towards downscaling of wireless communication devices, compactness of radiating elements with single antenna to support different technologies and standards becomes extremely important. As such, miniaturization with multi frequency resonating microstrip patch antennas is desired without sacrificing their performance.

There are several papers on dual band or multiband antennas $[1,2]$ by using traditional methodology like use of slots, defected ground structures (DGS), dielectric materials with high-permittivity, ceramic substrates. But recently, there has been a growing interest in artificial materials (i.e., metamaterial) [3] on antennas to drastically reduce their size [4]. One of the most commonly used elements of metamaterial is split ring resonator which was designed by Pendry in 1999. The characteristics of the split ring resonator have already been studied by many researchers [5]. In its complementary structure, the CSRRs behaves as an electric dipole excited by an axial electric field to create an effective negative $\varepsilon$ medium and inhibit signal propagation at resonance [6]. A technique of stub loaded complimentary dual split and single split ring resonator on the radiating patch is employed here to realize a compact and multiband microstrip patch antenna. Simulated [7] and experimental studies of the proposed antenna are presented and discussed.

\section{DESIGN OF ANTENNA AND CSRR STRUCTURE}

Fig. 1(a) shows the top view of proposed geometry of the conventional rectangular microstrip patch antenna which is designed by using low cost FR4 material having dielectric constant $\mathrm{gr}=4.4$ and thickness $\mathrm{h}=1.6 \mathrm{~mm}$. The conventional microstrip antenna is designed for $6 \mathrm{GHz}$ with patch dimensions $\mathrm{L}=11.33 \mathrm{~mm}$ and $\mathrm{W}=15.25 \mathrm{~mm}$ fed by a $50 \Omega$ center fed microstripline feed having dimensions $\mathrm{Lf50}=6.187 \mathrm{~mm}$ and Wf50 $=3.060 \mathrm{~mm}$ through a quarter wave transformer of dimension $\mathrm{Lt}=4.92 \mathrm{~mm}$ and $\mathrm{Wt}=$ $0.50 \mathrm{~mm}$. The length $\mathrm{Lg}=40 \mathrm{~mm}$ and $\mathrm{Wg}=40 \mathrm{~mm}$ of the ground plane of the antenna is calculated by $\mathrm{Lg}=6 \mathrm{~h}+\mathrm{L}$ and $\mathrm{Wg}=6 \mathrm{~h}+\mathrm{W}$.

The study is carried by loading a stub at the middle of the radiating edge of MSA with $\mathrm{Ls}=4 \mathrm{~mm}$ and $\mathrm{Ws}=2 \mathrm{~mm}$ which is named as stub loaded microstrip antenna (SMSA) and is shown in Fig. 1(b). Next the SMSA is loaded with optimized dual spilt ring resonator of $S_{L}=3.6 \mathrm{~mm}$, $\mathrm{S}_{\mathrm{W}}=0.2 \mathrm{~mm}, \mathrm{~S}=0.2 \mathrm{~mm}, \mathrm{~g}=0.2 \mathrm{~mm}$ which is named as stub loaded complimentary dual spilt ring resonator microstrip antenna (SCDSR-MSA) shown in Fig. 1(c). Finally by maintaining all parameters of the SCDSR-MSA constant, only the dual spilt is converted to single spilt which is named as stub loaded complimentary spilt ring resonator microstrip antenna (SCSR-MSA) is shown in Fig. 1 (d). The Figs. 2(a), (b) and (c) are enlarged structures of proposed stub, DSCSRR and SCSRR respectively. Fig. 3 shows the photographic view of the proposed microstrip patch antenna (a) Conventional (b) SCSR-MSA. 


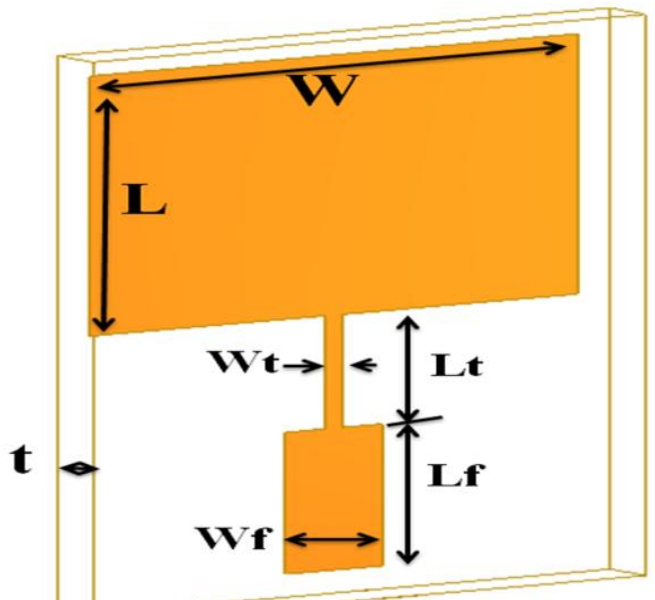

(a)

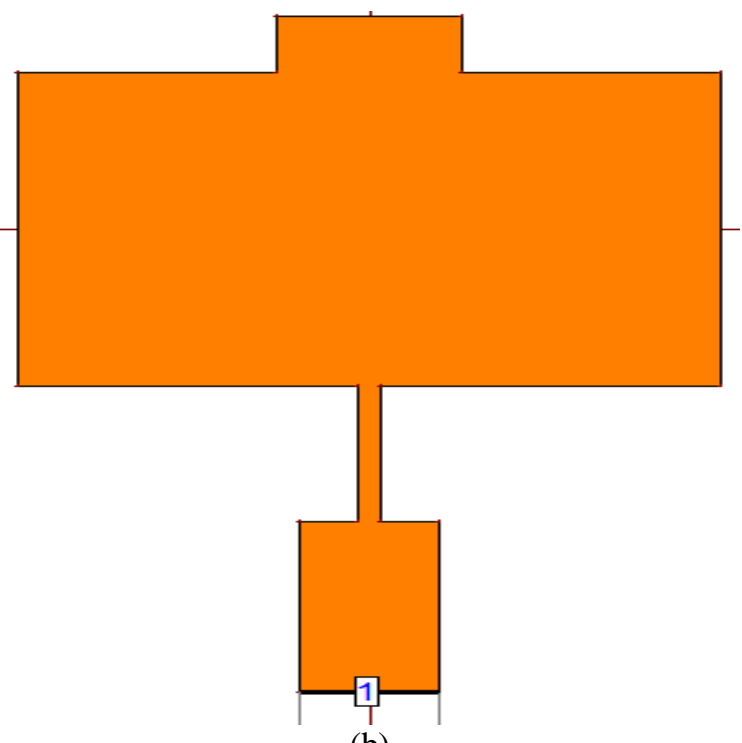

(b)

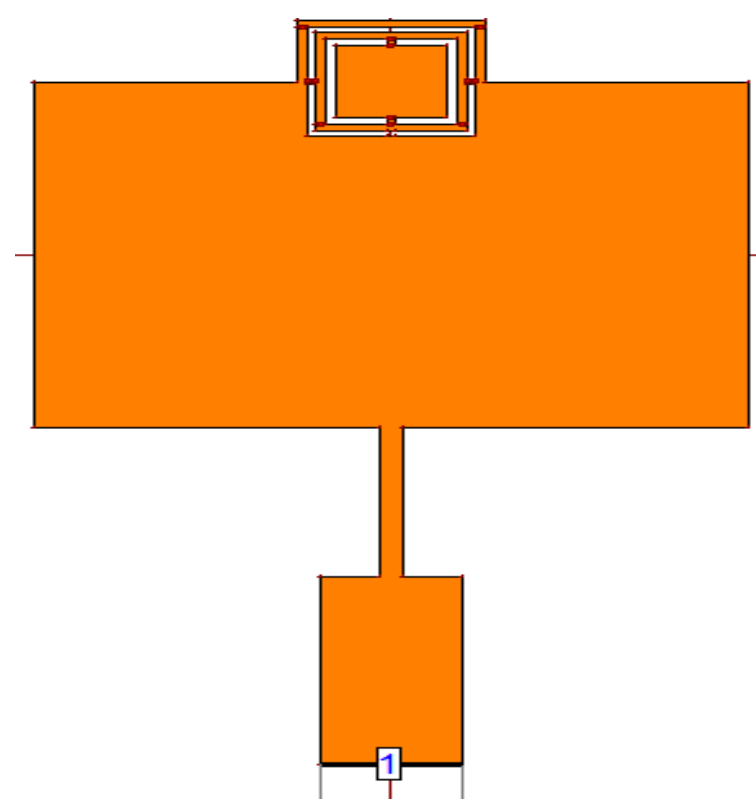

(c)

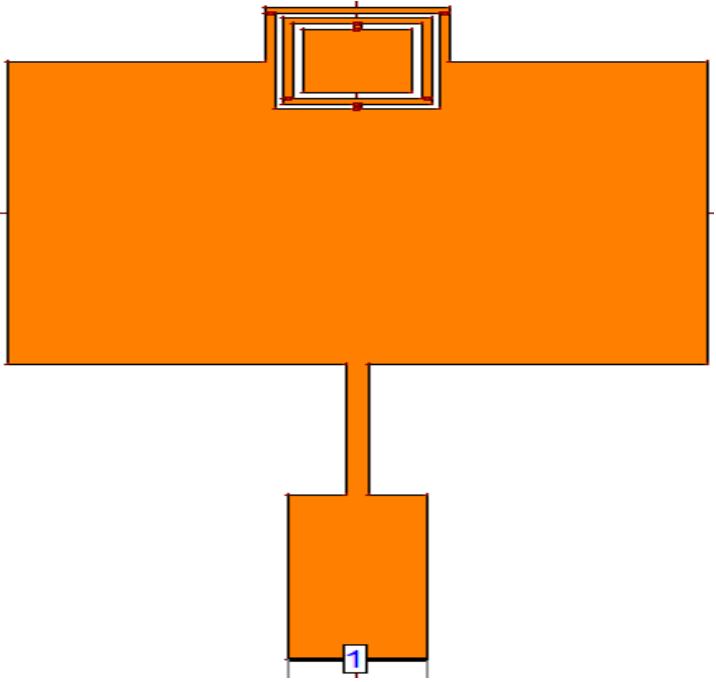

(d)

Fig -1: Geometries of proposed microstrip patch antenna (a) Conventional (b) SMSA (c) SDSCSR-MSA (d) SCSR-MSA

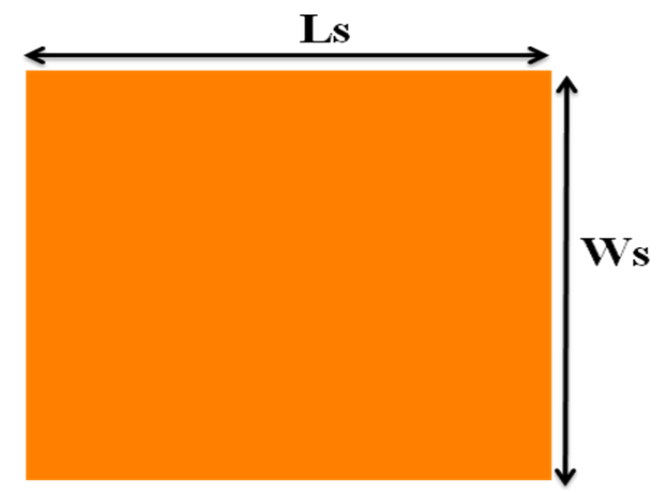

(a)

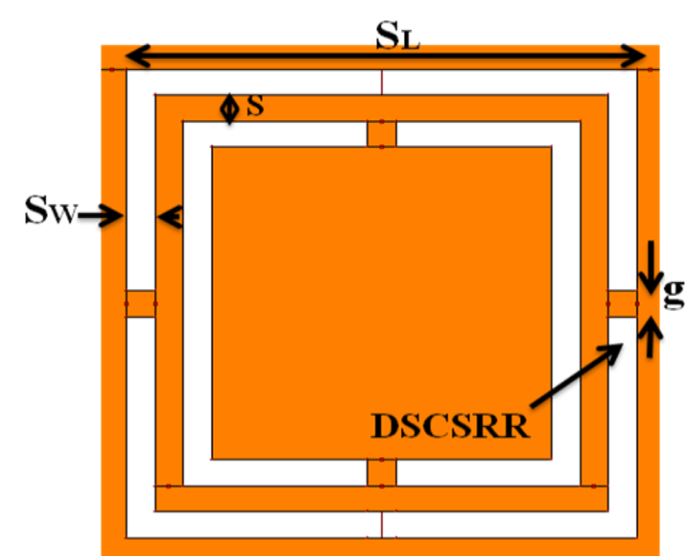

(b) 


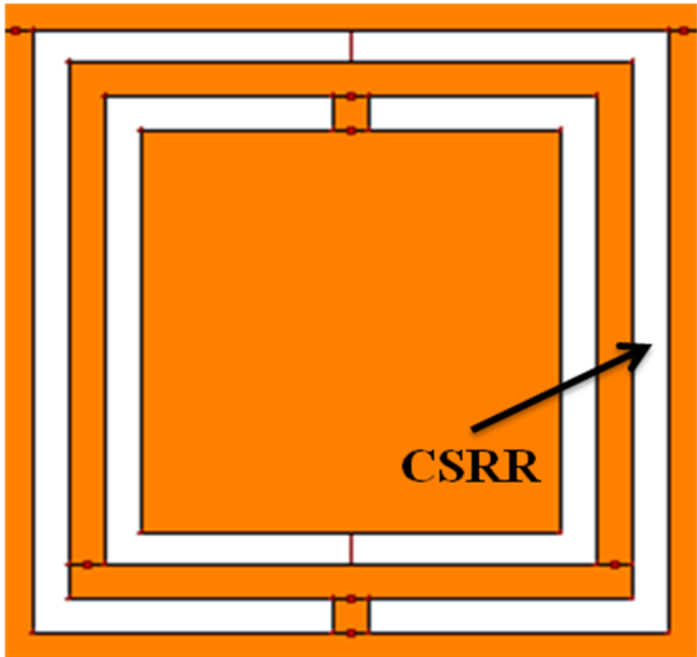

(c)

Fig-2: Enlarged structures of proposed (a) Stub (b) DSCSRR (c) SCSRR

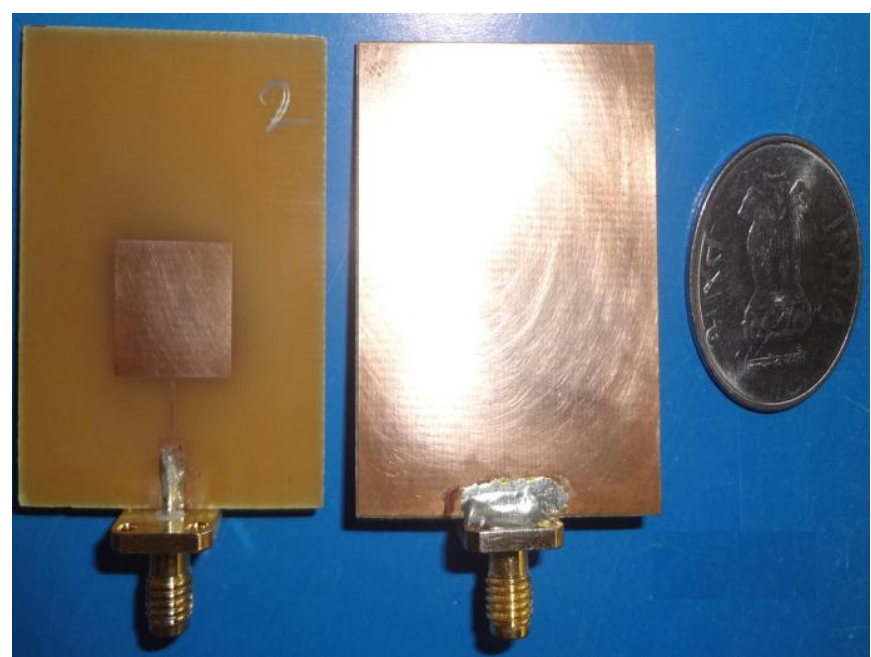

(a)

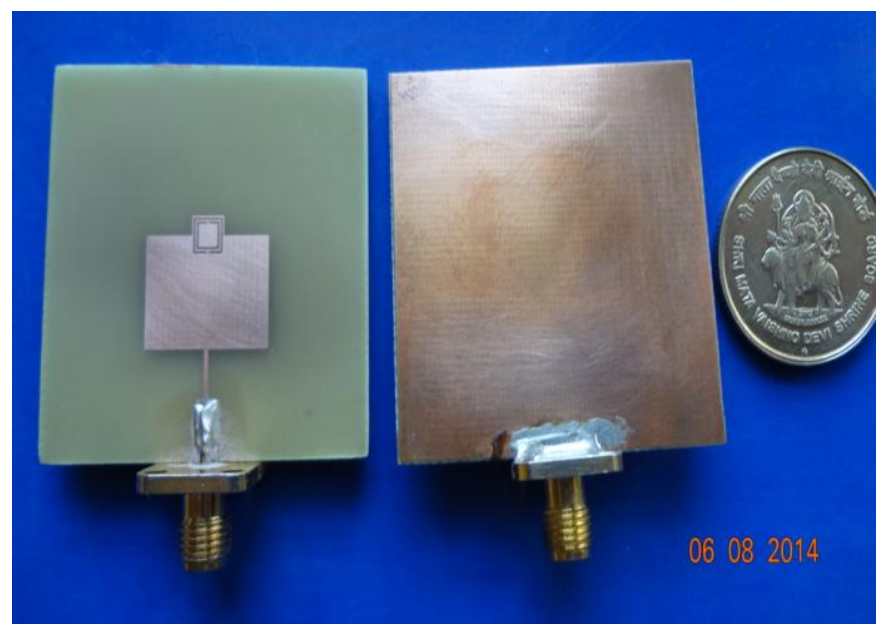

(b)

Fig.-3: Photographic view of the proposed microstrip patch antenna (a) Conventional (b) SCSR-MSA

\section{RESULTS AND DISCUSSIONS}

The simulation is carried out by using the mentor graphics IE3D simulation software version 14.65 [5]. The parameters of the proposed antennas are measured on Vector Network Analyzer (VNA) (Rhode and Schwarz, Germany make ZVK model 1127.8651).

Fig. 4 shows the simulated return loss characteristics of conventional MSA with SMSA, SCDSR-MSA and SCSRMSA. Table 1 shows the results of simulated parameters of all the proposed antennas. The impedance bandwidth over return loss less than $-10 \mathrm{~dB}$ is determined by using the equation

$$
B W=\left[\frac{f 2-f 1}{f c}\right] \times 100 \%
$$

Where, $\mathrm{f} 1$ and $\mathrm{f} 2$ are the lower and upper cut-off frequencies of the band respectively, when its return loss reaches -10dB and $\mathrm{fC}$ is the centre frequency between $\mathrm{f} 1$ and $\mathrm{f} 2$.

After the simulations of all the proposed MSAs, the conventional MSA and optimized antenna (i.e., SCSRMSA) is fabricated and measured. The conventional MSA is resonating at $\mathrm{Fr}=5.97 \mathrm{GHz}$ with bandwidth of $240 \mathrm{MHz}$. But the SCSR-MSA is resonating with four different frequency points Fr1 $=4.96 \mathrm{GHz}, \operatorname{Fr} 2=6.02 \mathrm{GHz}, \mathrm{Fr} 3=8.62 \mathrm{GHz}$ and $\mathrm{Fr} 4=11.25 \mathrm{GHz}$ with bandwidths of $59 \mathrm{MHz}, 109 \mathrm{MHz}$, $531 \mathrm{MHz}$, and $984 \mathrm{MHz}$ respectively. The measured return loss characteristics are compared with that of simulated values and the results are shown in Table 2. Fig.5 shows the simulated and measured return loss characteristics of the Conventional MSA and Fig. 6 shows the simulated and measured return loss characteristics of the SCSR-MSA. It is observed from the figures that, all the simulated and measured results are in good agreement with each other. 


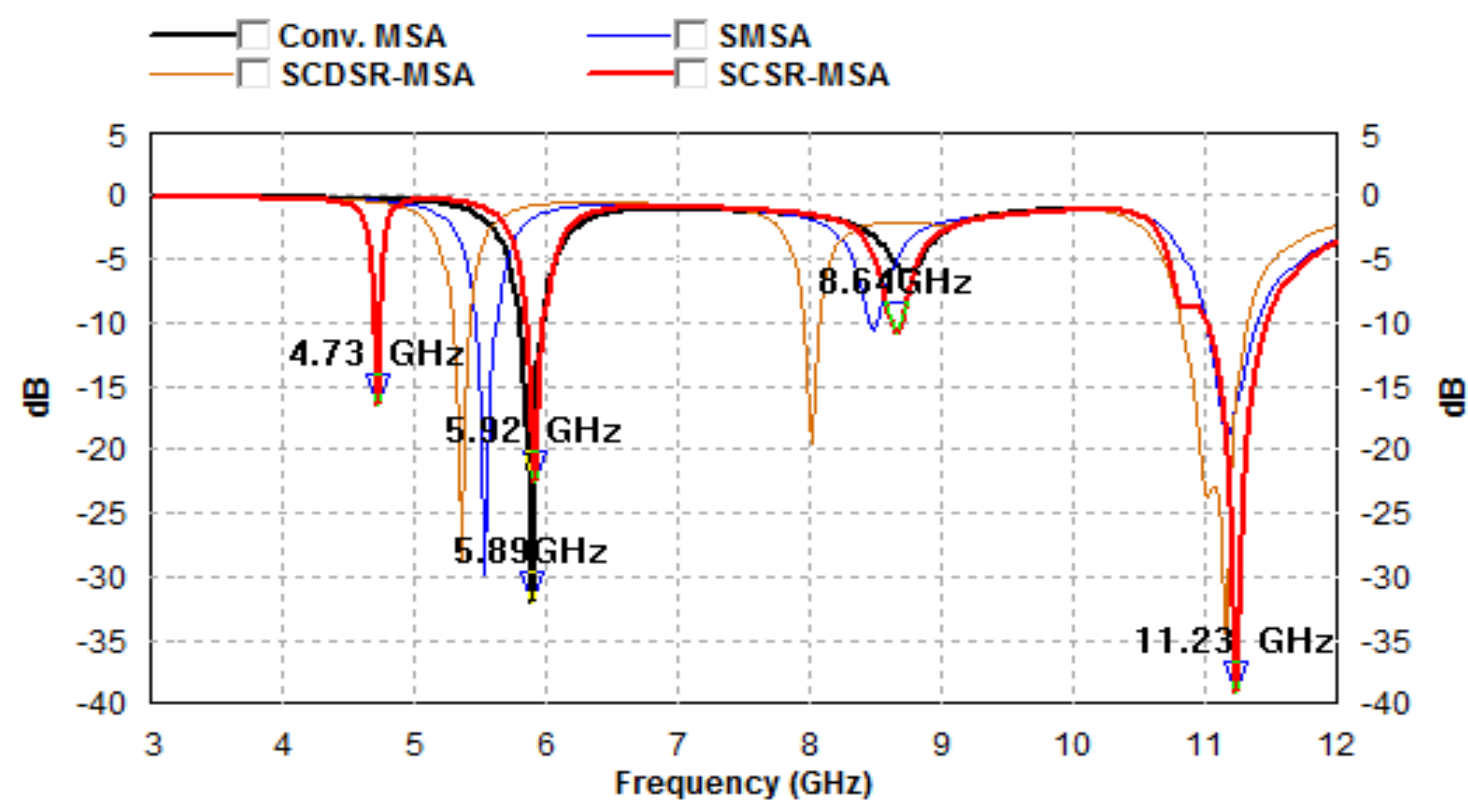

Fig-4: Return loss characteristics of proposed antennas with and without metamaterials

Table -1 Simulated results of proposed antennas

\begin{tabular}{|l|l|l|l|l|}
\hline $\begin{array}{l}\text { Antenna } \\
\text { configurations }\end{array}$ & $\begin{array}{l}\text { Resonating } \\
\text { Frequency } \\
(\mathbf{G H z})\end{array}$ & $\begin{array}{l}\text { Minimum } \\
\text { Reflection } \\
\text { Co- } \\
\text { efficient } \\
(\mathbf{d B i})\end{array}$ & $\begin{array}{l}\text { Bandwidth } \\
\text { (MHz) }\end{array}$ & $\begin{array}{l}\text { Band } \\
\text { width } \\
(\mathbf{\%})\end{array}$ \\
\hline Conv. MSA & 5.89 & -33.95 & 180 & 2.99 \\
\hline \multirow{3}{*}{ SMSA } & 5.54 & -27.80 & 152 & 2.74 \\
\cline { 2 - 5 } & 8.84 & -10.60 & 64 & 0.72 \\
\cline { 2 - 5 } & 11.16 & -19.09 & 384 & 3.44 \\
\hline \multirow{5}{*}{ SCDSR-MSA } & 5.36 & -28.68 & 130 & 2.42 \\
\cline { 2 - 5 } & 8.01 & -19.49 & 125 & 1.56 \\
\cline { 2 - 5 } & 11.16 & -34.64 & 487 & 4.36 \\
\hline \multirow{3}{*}{ SCSR-MSA } & 4.73 & -16.44 & 44 & 0.93 \\
\cline { 2 - 5 } & 5.92 & -22.50 & 133 & 2.24 \\
\cline { 2 - 5 } & 8.64 & -10.78 & 73 & 0.84 \\
\cline { 2 - 5 } & 11.23 & -39.07 & 227 & 2.02 \\
\hline
\end{tabular}

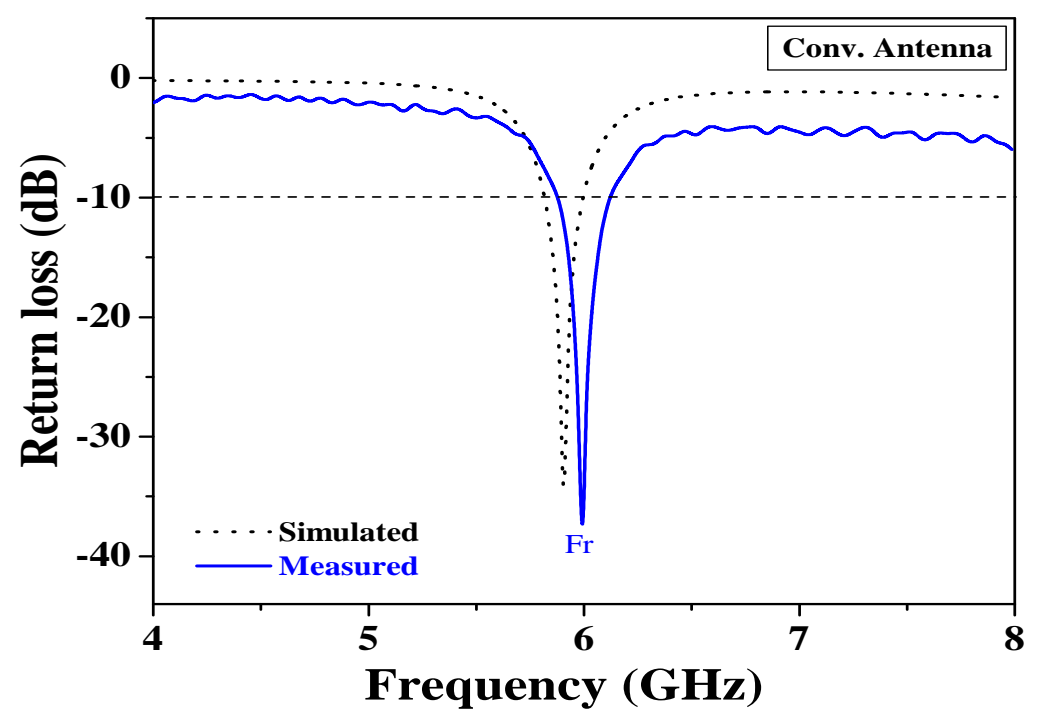

Fig.-5: Simulated and measured return loss characteristics of conventional antenna 


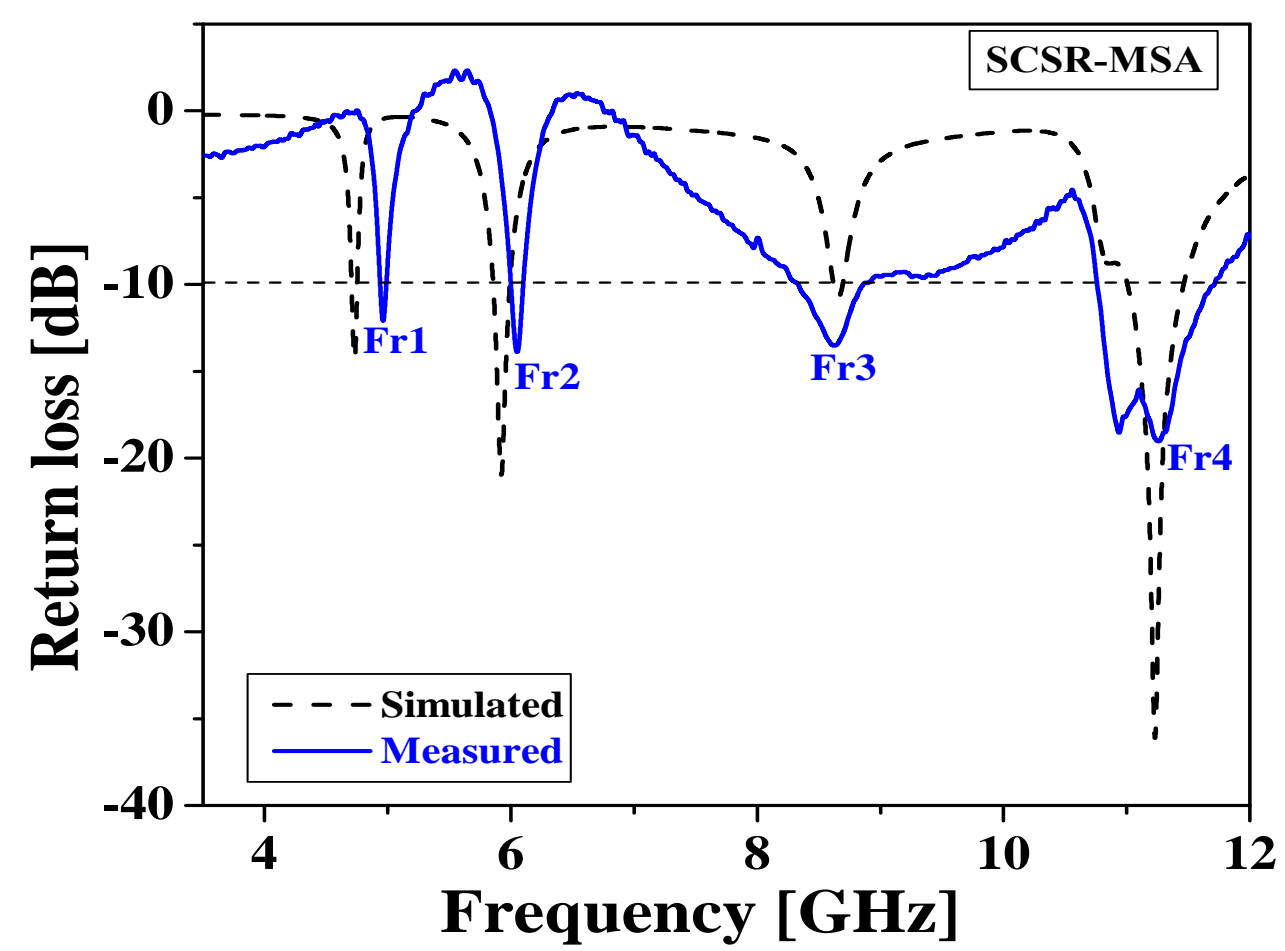

Fig-6: Simulated and measured return loss characteristics of SCSR-MSA

Table-2 Comparison of Simulated and measured results of proposed antennas

\begin{tabular}{|c|c|c|c|c|c|c|c|c|}
\hline $\begin{array}{l}\text { Antenna } \\
\text { configurations }\end{array}$ & \multicolumn{2}{|c|}{$\begin{array}{l}\text { Resonating } \\
\text { Frequency } \\
(\mathbf{G H z})\end{array}$} & \multicolumn{2}{|c|}{$\begin{array}{l}\text { Minimum Reflection } \\
\text { Co-efficient (dBi) }\end{array}$} & \multicolumn{2}{|c|}{ Band Width (MHz) } & \multicolumn{2}{|c|}{ Bandwidth (\%) } \\
\hline & Sim & Pract & Sim & Pract & Sim & Pract & Sim & Pract \\
\hline Conv. MSA & 5.89 & 5.97 & -33.95 & -42.40 & 180 & 240 & 2.99 & 4.02 \\
\hline \multirow{4}{*}{ SCSR-MSA } & 4.73 & 4.96 & -16.44 & -12.00 & 44 & 59 & 0.93 & 1.18 \\
\hline & 5.92 & 6.05 & -22.50 & -13.84 & 133 & 109 & 2.24 & 1.80 \\
\hline & 8.64 & 8.62 & -10.78 & -13.51 & 73 & 531 & 0.84 & 6.16 \\
\hline & 11.23 & 11.25 & -39.07 & -18.99 & 227 & 984 & 2.02 & 8.74 \\
\hline
\end{tabular}

Fig. 7(a) and Fig. 7(b) shows the radiation patterns of conventional MSA and SCSRRMSA at their operating bands. From these figures it is seen that, the patterns are broadside in nature in both the cases. Fig. 8(a) shows vector current distribution of conv. antenna at $5.89 \mathrm{GHz}$ and Fig. 8(b) shows SCSR-MSA at 4.73GHz. Fig. 9 shows enlarged view of vector current distribution of SCSR-MSA. From this figure we can observe that the CSRR disturb the currents flowing on the surface, forcing them to meander and thus the electrical length of the patch antenna increases in the radiating edge. Accordingly, the operating frequency decreases, where as the physical size of the patch is unaffected. 

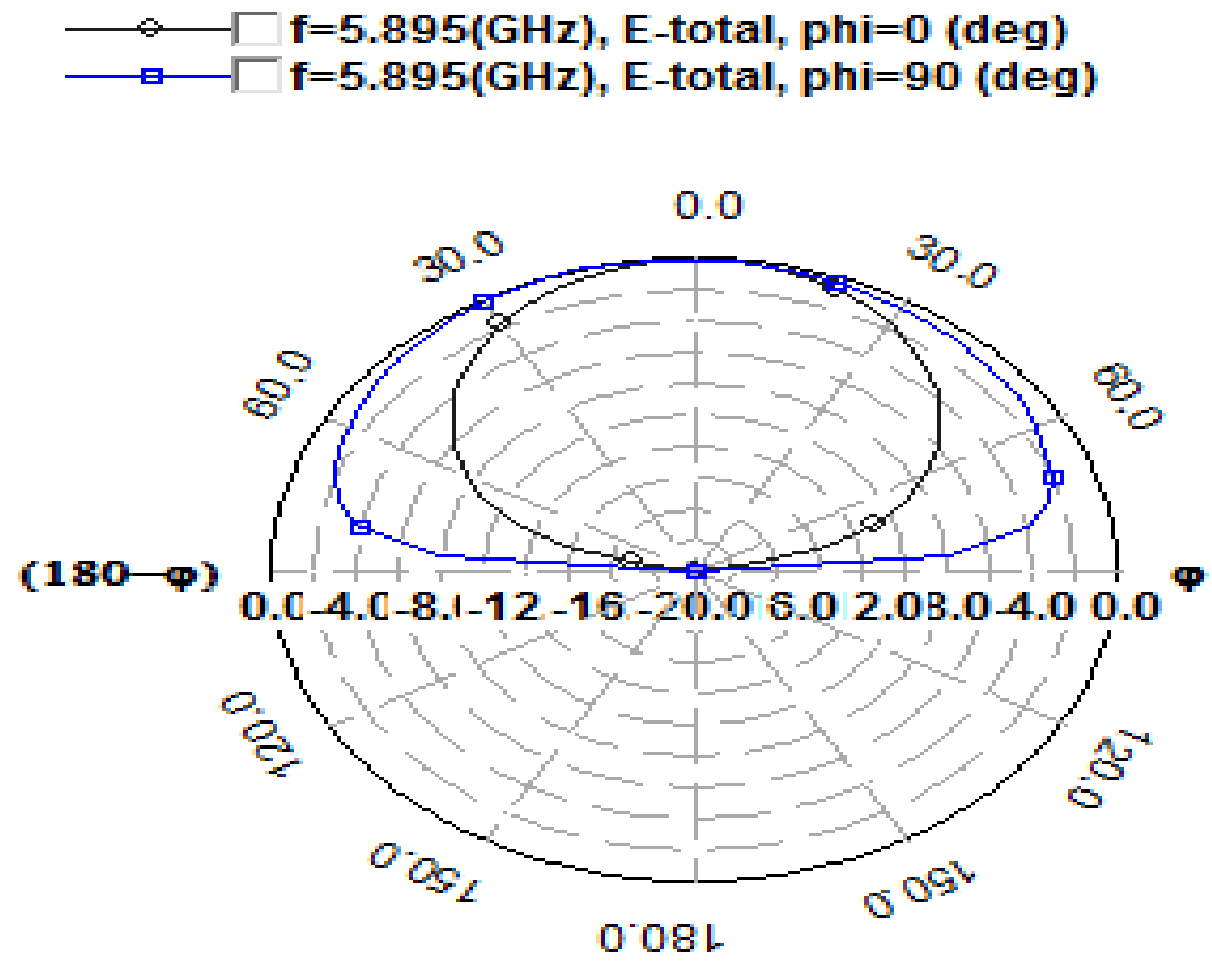

Elevation Pattern of Con. Antenna

(a)
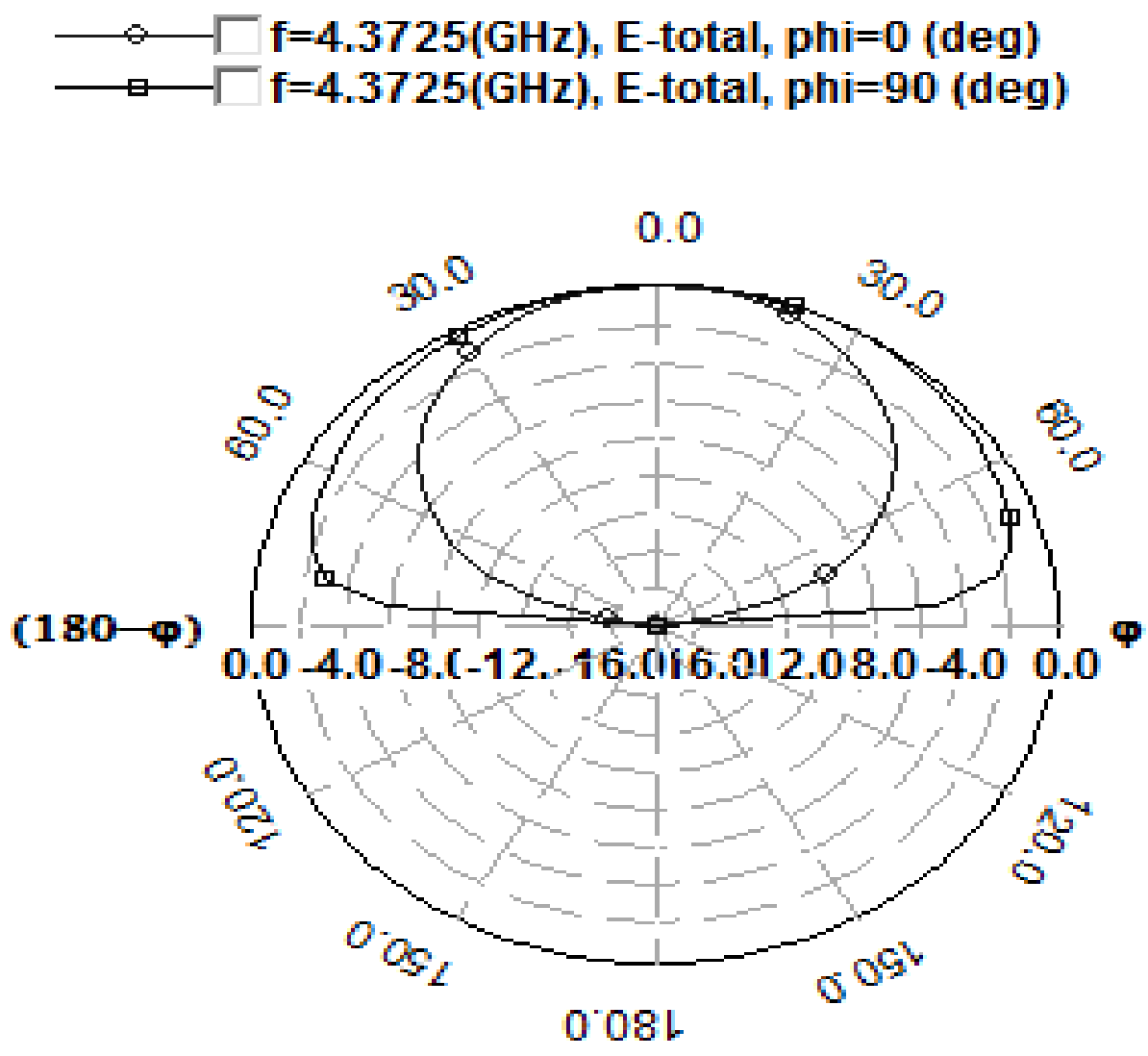

Elevation Pattern of SCSRRMSA

(b)

Fig-7: (a) Radiation pattern of Conv. antenna at $5.89 \mathrm{GHz}$ (b) SCSR-MSA at $4.37 \mathrm{GHz}$ 


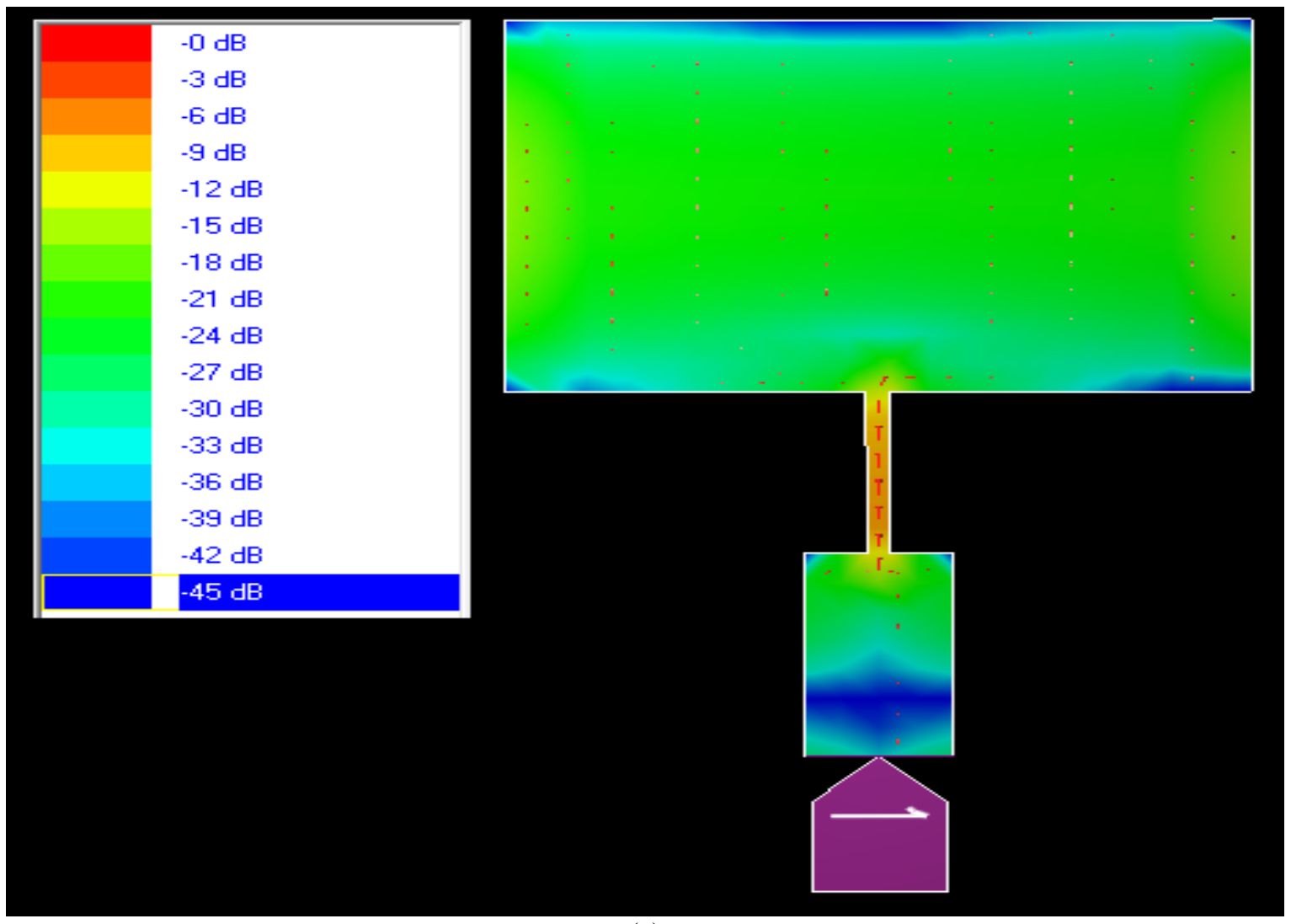

(a)

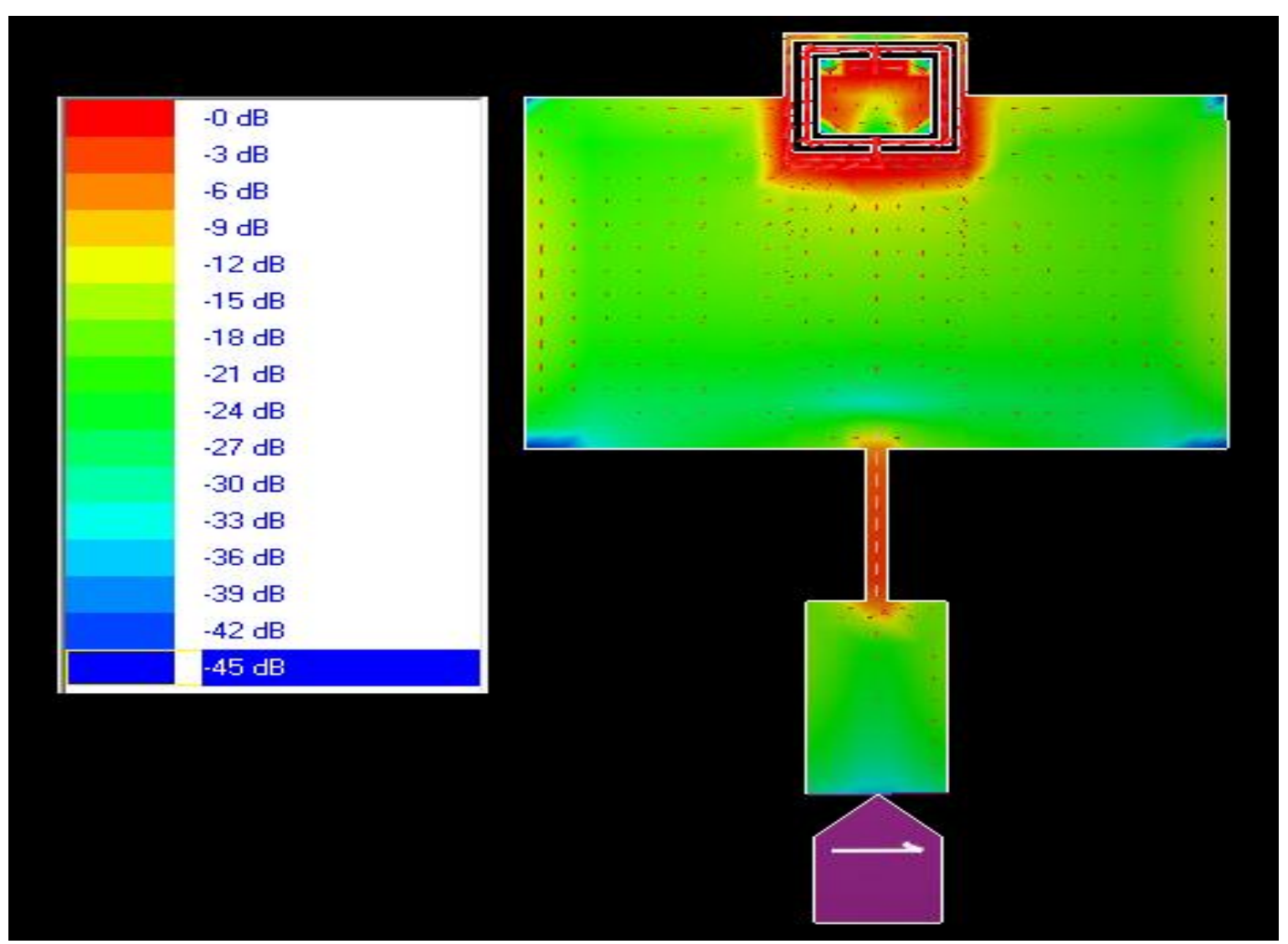

(b)

Fig-8: (a) Vector Current distribution of conv. antenna at $5.89 \mathrm{GHz}$ and (b) SCSR-MSA at $4.73 \mathrm{GHz}$ 


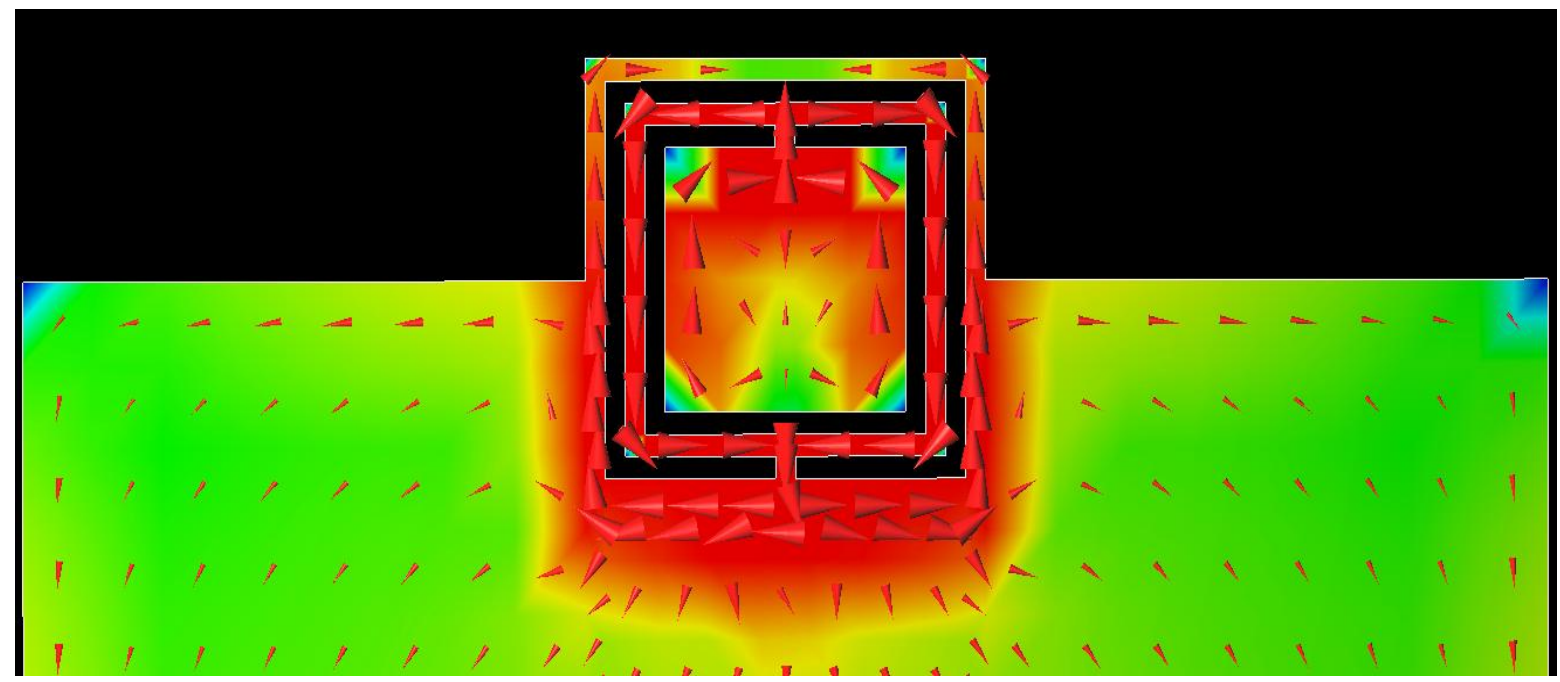

Fig-9: Enlarged view of vector current distribution of SCSR-MSA

\section{CONCLUSION}

In conclusion, a technique for size reduction and multiband microstrip patch antennas are presented. The proposed methodology employs CSRRs that are etched out from the radiating edges of the patch antennas has been proposed. The technique is simple and easy to fabricate using traditional milling techniques. It was found that a size reduction of almost $16.92 \%$ with multiband resonating frequencies is achieved for microstrip patch antenna with stub loaded complimentary split ring resonator is etched in the radiating edges of the patch antenna. The proposed antenna with good performance is suitable for several wireless applications and X-band communication.

\section{ACKNOWLEDGEMENTS}

The authors acknowledge their thanks to UGC, New Delhi for sanctioning of the IE3D simulation software under Major research project which is most useful and reliable for designing microstrip antennas.

\section{REFERENCES}

[1] 1.R K Raj , M. Joseph, C. k. Ananadan, K. Vasudevan and P. Mohan "A new compact microstrip-fed dual-band coplanar antennas for WLAN applications", IEEE Trans. Antennas Propag., Vol. 54, No. 12, pp. 3755-3762, Dec. 2006.

[2] 2.J. W. Wu, H. M. Hsiao, J. H. Lu and S. H. Chang, "Dual broadband design of rectangular slot antennas for 2.4 and 5 Ghz wireless", IEE Electron Lett, Vol. 40, No. 23, Nov 2004.

[3] 3. V. G. Veselago " The electrodynamics of substances with simultaneously negative values of $\varepsilon$ and $\mu$, SovPhys Usp 10 (1968), pp. 509-514.

[4] D. Laila, R. Sujath, V. A. Shameena, C. M. Nijas, V. P. Sarin and P. Mohanan, "Complementory split ring resonator based microstrip antenna for compact wireless applications", MOTL, Vol. 55, No.4, April 2013, pp. 814-816.

[5] 4. D. R. Smith, W. J. Padilla, D. C. vieer, S. C. Nermat-Nasser and S. Schultz, "Negative permeability from split ring resonator arrays", Phys Rev Lett 84 (2000).

[6] 5. I. Gil, J. Bonache, M. Gil, J. Garcia-Garcia, F. Marin and M. Sorolla, "Effective negative- $\varepsilon$ stopband microstrip lines based on CSRRs", IEEE Microwave wireless compon Lett 14 (2014), 280282.

[7] Zeland Mentor Graphics IE3D simulation Software version 14.65, 2010.

\section{BIOGRAPHIES}

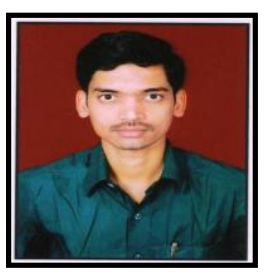

Prashant R. T received his M Sc from the department of Applied Electronics Gulbarga University, Gulbarga in the year 2011. He worked as a Project Fellow in the UGC sponcerd Major Research Project during the year 20122013. Currently he is persuing his Ph.D in the field of Microwave Antennas from the department of Applied Electronics, Gulbarga University, Gulbarga.

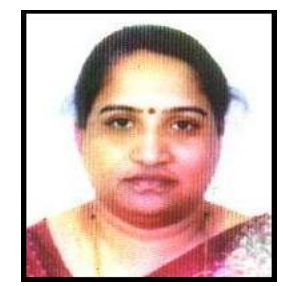

Vani R. M received her B.E. in Electrical and Electronics from the B.I.ET., Davanagere and M.Tech in Industrial Electronics from S.J.C.E., Mysore, Karnataka. She has received her Ph.D in Applied Electronics from Gulbarga University, Gulbarga, India, in year 2005. She is working as Professor \& Head, University Science Instrumentation Center, Gulbarga University, Gulbarga. She has more than 85 research publications in national and international reputed journals/Conference proceedings. she presented the research papers in National/ International conferences in India and abroad. She has conducted several courses, workshops for the benefits of faculties and field engineers. Her areas of interest are microwave antennas, PC based instrumentation, embedded controllers and Wireless communication. She has one UGC major research project to her credit. 


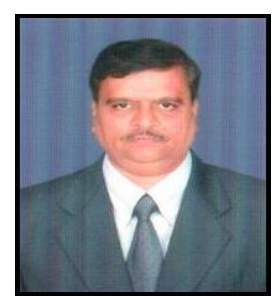

P. V. Hunagund received his M. Sc and Ph. D from the Dept. of Applied electronics, Gulbarga University, Gulbarga, in the year 1982 and 1992 respectively. $\mathrm{He}$ is working as Professor and Chairman of Applied Electronics department, Gulbarga University, Gulbarga. He has more than 100 research publications in national and international reputed journals, more than 150 research publications in international symposium/Conferences. He has presented the research papers in National/International conferences in India and abroad. He has guided many Ph.D and M.Phil students. He has three major research projects at his credit. He has worked as a committee member in various selection committees for selection of Associate Professor and Professor in different Universities. 